\title{
RÔZNE POHLADY NA ZODPOVEDNOSŤ V ZDRAVOTNÍCKOM SYSTÉME
}

\author{
Zuzana Kaššaiová
}

\begin{abstract}
Abstrakt
Veda a technológie idú neuveritel'nou rýchlost'ou dopredu. Napriek tomu má zdravotnícky systém vel'a nedostatkov a medicínske chyby sa stávajú neustále. V posledných rokoch sa pozornost' upriamuje na zlepšenie kvality zdravotnej starostlivosti. Podl'a štatistík z národných štúdií v rôznych európskych krajinách, $8-10 \%$ chýb je spôsobené l'udským faktorom. $V$ tomto texte som prebrala najzákladnejšie koncepty individuálnej a kolektívnej zodpovednosti a poukazujem na to, že v zdravotníckom systéme sú jednotlivci častokrát súčast'ou tímov a nie je možné jednoznačne určit' individuálnu zodpovednost'. Napriek tomu prevladajúca kultúra viny smeruje k sankciovaniu jednotlivca. Domnievam sa, že aktuálnost' témy na Slovensku aj v Českej republike je posilnená zvyšujúcim sa počtom prípadov pochybení, ktoré sú rozoberané v médiách. Preto poukazujem aj na možný dopad médií a kultúry viny na zdravotníckeho profesionála, ktorý pochybí, a zároveň dochádzam k záveru, že obviňovanie jednotlivca nerobí systém bezpečnejším. Naše zameranie by skôr malo smerovat' na preukázanie, že jednotlivec môže byt' neopatrný. Ale ak sa už stane chyba, apelovat' by sme mali na zlepšenie systému a prevenciu pred rovnakými chybami. Iba takto dokážeme premenit’ kultúru viny na kultúru bezpečnosti a zlepšit' zdravotnú starostlivost'.
\end{abstract}

Klúčové slová: zdravotnícky systém, zodpovednost', kultúra viny, média

\section{DIFFERENT OPINIONS ON RESPONSIBILITY IN HEALTHCARE SYSTEM}

\begin{abstract}
The science and technology are evolving incredibly fast. Despite that, the healthcare system has a lot of insufficiencies and medical failures happen consistently. In recent years the focus has been on increasing the quality of healthcare. According to statistics from national studies from different European countries, 8 to $10 \%$ of mistakes are being caused by the human factor. In this text I discuss the most fundamental concepts of individual and collective guilt and point out that in healthcare system are individuals often part of a team and it is not possible to determine unambiguously the individual responsibility. In spite of this the dominant culture of guilt tends to penalize the individual. In my opinion, the urgency of this topic in Slovakia and The Czech Republic is emphasized by the increasing number of cases of failure which are being discussed in the media. Therefore I point out even possible impact of media and the guilt culture on the medical professional who fail and simultaneously I conclude that blaming the individual does not make the system safer. Our focus should rather be centred on showing that an individual can be incautious. However when the mistake happens we should appeal to improving the system and a prevention of this type of mistakes. Only this way we can change the culture of guilt to a culture of safety and improve the healthcare.
\end{abstract}

Keywords: healthcare system, responsibility, culture of guilt, media

Došlo: 20.11.2018

Schváleno: 2. 8. 2019 
„16-ročnej prvorodičke sestra na gynekologickom oddelení omylom podala intravenózne epidurálnu anestéziu namiesto antibiotík. Dievča utrpelo záchvat a zomrelo. Diet’a sa podarilo zachránit'."

(ASQ, 2007)

„10-ročný chlapec z Indie bol prijatý na pediatrickú ambulanciu z dôvodu očkovania. Chlapec bol v dobrom zdravotnom stave, všetky očkovania boli aktualizované $s$ výnimkou hepatitídy B. Lekár diskutoval o potrebe očkovania s otcom chlapca a napokon sa rozhodli chlapca zaočkovat'. Po podaní látky lekár zistil, že podal dávku vakciny pre hepatitídu A namiesto hepatitídy $B$.“

(Gallagher, \& Levinson, 2004)

Cicero si kládol otázku: „Je prirodzené pre človeka, že sa dopúšt’a chýb? “James Reason (1990) rozumie pod l'udskými chybami všetky situácie, v ktorých nie je možné dosiahnut' plánované sekvencie mentálnych alebo fyzických aktivít a tieto zlyhania nemožno pripísat' zásahu nejakej náhodnej udalosti. Podl'a Ernsta Macha (dle Reason, 1990) znalosti a chyby vychádzajú z rovnakých mentálnych zdrojov. Iba úspech nám hovorí, čo je znalost' a čo chyba. Gorovitz a MacIntyre (1975) hovoria o „nevyhnutných omyloch“ - niektoré veci, ktoré chceme urobit', sú mimo našu kapacitu. Napriek zdokonaleniu technológií, naše mentálne a psychické sily sú obmedzené a vel'ká čast' sveta a vesmíru je - a ostane - mimo nášho chápania a kontroly. Avšak existujú sféry, kde kontrolu máme - postavit' mrakodrapy, predpovedat' snehové búrky, zachránit' pacienta pred srdcovým infarktom.

V týchto sférach existujú iba dva dôvody zlyhania. Prvým je nevedomost' - môžeme sa mýlit', pretože veda nám dala len čiastočné pochopenie sveta - mrakodrapy, ktoré ešte nevieme postavit', snehové búrky, ktoré ešte nevieme predpovedat', ochorenia, ktoré ešte nevieme vyliečit'. Druhým dôvodom je hlúpost' - pretože v týchto prípadoch existujú vedomosti, ale nevyužívame ich správne. Ako mrakodrap, ktorý sa zrúti alebo človek s infarktom, ktorý chybou zdravotníkov umrie.

V tomto storočí sa výrazne zmenila rovnováha medzi nevedomost'ou a hlúpostou. Nevedomosti môžeme odpustit' neúspech, pretože ak chýba vedomost', sme radi, že l'udia vynaložili maximálne úsilie. Dnes však poznáme vel’a rôznych spôsobov ako znížit', napríklad, pravdepodobnost' srdcového záchvatu. Ako je teda možné, že 20 - $30 \%$ pacientov prijíma kontraindikovanú starostlivost' (Starfield, 2000)? A čo myslíme tým, že pri 8 - $12 \%$ hospitalizácií lekárske chyby a chyby v zdravotnej starostlivosti súvisia s nežiaducimi účinkami (Waldman, Smith, 2012)? Ak teda vedomosti existujú a nie sú správne aplikované, je t’ažké nebyt' nahnevaný. Gorovitz a MacIntyre (1975) to nazývajú hlúpost'ou, avšak niektorí (Oyebode, 2006) použivajú slová ako nedbalost' či dokonca bezcitnost'. 


\section{Medicínske chyby a zodpovednost'}

Ak sa hovorí o medicínskych chybách, pozornost' sa upriamuje zväčša na zdravotnícky systém a jeho slabiny, no zahŕňa aj právnické, etické a ekonomické stránky. Podl'a Svetovej zdravotníckej organizácie (2017) je pacientova bezpečnost' globálnou verejnou prioritou. Zdravotnícke chyby sú dôsledkom nielen objektívnych faktorov, ako nedokonalost' lekárskej vedy či nedostatok pracovných podmienok, ale vyplývajú aj zo subjektívnych faktorov, ako napríklad nedbanlivost' či nedostatok vedomostí (Stoyanova, Raycheva, \& Dimova, 2012). Waldman a Smith (2012) uvádzajú, že približne $5 \%$ všetkých pacientov prijatých do britských nemocníc má negatívnu skúsenost', ktorej sa dá predchádzat'. Vo Vel'kej Británii v roku 2000 nahlásila „An Organization with memory“ 850000 nežiaducich účinkov ročne, čo je približne 10 \%. Rovnaké výsledky priniesla v roku 2005 národná štúdia v Španielsku, neskôr Francúzsko a Dánsko publikovalo podobné výsledky (WHO, 2017). Na Slovensku a v Českej republike neexistuje súhrnná evidencia medicínskych pochybení, ale v roku 2010 slovenský Úrad pre dohl'ad nad zdravotnou starostlivost'ou (d'alej ÚDZS) riešil 1469 st'ažností v oblasti poskytovania zdravotnej starostlivosti, z toho 245 uznal ako opodstatnené (Bendová \& Vaverková, 2012). V roku 2016 ÚDZS riešil celkovo 870 st’ažností, pričom 172 (19,77\%) z nich vyhodnotil ako opodstatnených. Podania sa týkali predovšetkým nespokojnosti s postupom pri liečbe $(56,16 \%)$ a úmrtia v súvislosti s poskytovanou zdravotnou starostlivost'ou (25,41 \%) (Gurňáková, 2017). Odhady presných čísel však variujú, či už v závislosti od kritérií hodnotenia, spôsobu nahlasovania alebo ochoty hlásit' takéto pochybenia.

Problematika zdravotnej starostlivosti nie je v centre pozornosti iba v posledných desat'ročiach. Za všeobecne uznávaným obdobím modernej éry zlepšovania kvality sa považuje publikácia „Hodnotenie kvality medicínskej starostlivosti“ od A. Donabediana (1966), v ktorej načrtol model a poukázal na hodnotenie troch oddelených prvkov: štruktúra (nastavenie, personál, technológie zodpovedné za poskytovanie zdravotnej starostlivosti); proces (diagnostika, liečba, preventívna starostlivost'); výsledky (všetky efekty starostlivosti na pacienta a populáciu).

Donabedian veril, že štruktúra vplýva na proces a proces na výsledky. Spolu tvoria základ pre efektívny súbor opatrení. Avšak tomuto modelu bolo vytýkané separátne hodnotenie prvkov, ktoré sa nepribližuje k reálnej medicínskej praxi, nakol'ko výsledok ovplyvňujú aj faktory mimo kontrolu zdravotníckeho personálu. Ideálne by sa tieto faktory mali skúmat' súčasne a snažit' sa nájst' spôsoby, ako zlepšit' jeden aspekt starostlivosti, ktorý následne pozitívne ovplyvní aj ostatné (Warrier \& Mcgillen, 2011). Ak sa však chceme zaoberat' problematikou zlepšenia zdravotnej starostlivosti, narážame na otázku alokácie zodpovednosti medzi organizačným systémom a odborníkmi ako jednotlivcami. Samotný termín zodpovednost' sa vzt'ahuje na potrebu viditel'ného a transparentného rozhodovacieho procesu v zdravotnej starostlivosti, ako aj spôsobu dosiahnutia tohto ciel'a (Nunes, Brandao, \& Rego, 2011). V počiatočnej fáze dominoval názor, že chyby v zdravotnej starostlivosti sú výsledkom individuálnych príčin. Postupne sa formoval názor, že chyby nie sú výsledkom individuálneho neúspechu, ale neodvratnou črtou zle navrhnutého systému (Leape et al., 2000). Scott D. Sagan (1993) po analýze nehôd ako Černobyl’ alebo po ropnej katastrofe Exxon Valdez poukázal, že po nehodách sa neuskutočnilo „učenie“, nepomohla decentralizácia autority alebo dokonca 
nebola uskutočnená a nedochádza k vykonaniu reálnych pokusov o zmenu v systémoch s katastrofálnym potenciálom. Charles Perrow (1999) tak dospel k názoru, že „systémové elity“ sa nestarajú o bezpečnost' a $\mathrm{v}$ dôsledku organizačnej politiky sa mnohé činy takmer neriešia. Ako reakcia sa začal presadzovat' systém a podporovat' kultúra, ktoré by zmiernili alebo eliminovali chyby (Leape et al., 2000). Takýto prístup však viedol k nesprávnemu priradeniu celej zodpovednosti za bezpečnost' pacientov systému (Wachter \& Pronovost, 2010). Namiesto prístupu „bez viny“ jednotlivca sa v súčasnosti čoraz viac upozorňuje na „kultúru spravodlivosti“, aby boli zodpovední jednotlivci rovnako ako systémy (Wachter, 2013). Jednotlivci, akokol'vek disciplinovaní, môžu robit' chyby v zle fungujúcom alebo navrhnutom systéme. Na druhej strane, hl'adanie systémových chýb v prípade človeka môže byt' rovnako neplodné.

Aj napriek úsiliu, neexistuje dostatok empirického a teoretického základu a všetky snahy o spravodlivé rozdelenia majú tendenciu byt' skôr normatívne a mechanické. Napr. Marxov „algoritmus“ rozlišuje medzi 3 typmi chýb: l'udskou chybou (neúmyselným činom); rizikovým správaním (prijatie správania, ktoré zdravotník nevníma ako potenciálne nebezpečné) a bezohl'adným správaním. Podl'a autora je iba posledná kategória vnímaná ako úmyselná a mala by byt' individuálne potrestaná. Ďalej navrhuje riešenia ako utišovanie a koučing (Marx, 2001).

Iný koncept ponúkajú Meadows, Baker, \& Butler (2005), ktorí vytvorili nástroj so sériami otázok, ktoré pomáhajú identifikovat' motívy, konanie a správanie jednotlivca v čase incidentu. Tieto nástroje však boli kritizované za príliš zjednodušujúci pohl'ad, kedy je možné jednoduché rozlišovanie medzi prijatel'ným a neprijatel'ným správaním (Dekker, 2012). James Reason (1997) však poznamenal, že v niektorých prípadoch sa vyžadujú sankcie, a je proti prirodzenej spravodlivosti, ak by sa nesankciovalo nebezpečné správanie. Navrhuje spravodlivú kultúru, v ktorej je atmosféra dôvery a l’udia sú povzbudzovaní či odmeňovaní za poskytovanie základných informácií súvisiacich s bezpečnost'ou, ale v ktorej bude jasné, čo je prijatel'né a čo neprijatel'né správanie.

Je však otázne, či je možné identifikovat' individuálny príspevok k bezpečnosti pacienta, ked' jednotliví prispievatelia zdravotnej starostlivosti sú zväčša súčast’ou tímov. Politický filozof Dennis Thompson (1980) nazýva bezpečnost' pacientov „problémom mnohých rúk“. Boskov (2003) výskum chirurgov počas tréningu demonštruje, ako sa zodpovednost' vytvára a presadzuje prostredníctvom opakovaných a kolektivizovaných vzorov vnímania, vysvetl'ovania, rozpoznávania a disciplinovania akcií a udalostí. Bell et al. (2011) hovoria o kolektívnej zodpovednosti, a teda zodpovednosti na úrovní individuálnej, zdravotníckych tímov a inštitúcií. Podl'a autorov by v rámci kolektívnej zodpovednosti mali inštitúcie vyvíjat' robustné reportovacie systémy, podporovat' klinikov po nepriaznivých udalostiach a medicínskych chybách a vyvíjat' spôsoby kompenzácie pacientov, ktorí sú poškodení týmito chybami. Organizácie by tiež mali presadzovat' udržanie kompetencií a zabezpečit' dodržiavanie kvality. Týmto autori pokračujú v sociologickej tradícii Émila Durkheima o hodnote sankciovania ako kolektívnej zodpovednosti, ktorá pomáha zviditel'nit' a posilnit' normy komunity (vrátane profesionálnej) a zvýšit' solidaritu s touto komunitou. Naopak, M. Weber a H. D. Lewis ostro vystúpili proti konceptu kolektívnej zodpovednosti. Weber (1978) tvrdí, že kolektívna zodpovednost' nemá zmysel, pretože nemôžeme izolovat' kolektívne činy 
od identických akcií mnohých, respektíve viacerých osôb. Skupiny, na rozdiel od jednotlivcov, ktorí do nich patria, nemôžu mysliet' ako skupina alebo formulovat' zámery, ktoré sa zvyčajne považujú za nevyhnutné k akcii. Podl'a Lewisa (1984), ak by sme mali brat' koncept kolektívnej zodpovednosti vážne, samotný koncept individuálnej morálnej zodpovednosti by sa narušil. Jeho útok bol založený na tom, že nikto nemôže byt' zodpovedný za činy druhej osoby. Hodnota patrí iba jednotlivcovi a on jediný je nositel'om morálnej zodpovednosti. Podl'a jeho idey, kolektívna zodpovednost' ničí základ západnej etiky, a to morálnu zodpovednost' jednotlivca. Jeden z kritikov kolektívnej zodpovednosti J. Narveson (2002) pokračuje v duchu Webera a Lewisa. Nositelia morálnej zodpovednosti musia byt' iba jednotlivci, pretože iba oni majú morálnu agendu.

Z tohto môžeme vyvodit', že zodpovednost' nie je jednotným konceptom - aj ked' by nám mohli protirečit' mnohí zástupcovia zdôrazňujúci individuálnu zodpovednost' ako prostriedok zlepšenia výkonu. Lerner \& Tetlock (1999) tvrdia, že existuje tak mnoho druhov zodpovednosti, kol'ko existuje odlišných vzt'ahov medzi l'ud'mi a organizáciami. To znamená, že zodpovednost' nie je jednoznačná a jednoduchá. Dobrou stránkou je, že ak môže mat' mnoho podôb, potom existujú alternatívne spôsoby, ako udržat' l'udí zodpovedných.

\section{Prevládajúca kultúry viny a jej dopad}

V súčasnej kultúre nie je nič neobvyklé, že vinníkmi nejakého nešt’astia sú takzvaní vonkajší nepriatelia systému. Odobratie odznakov, certifikátov, licencií alebo iného označenia totožnosti a statusu v dôsledku nehody delegitimizuje člena komunity (Ballantyne, 2002). Táto delegitimizácia $\mathrm{v}$ podstate ul’ahčuje kriminalizáciu tým, že začína postupný proces dehumanizácie jednotlivca.

Wilkinson (1994) predstavuje príklad demobilizácie kapitána British Airways B-747. Kapitán bol obvinený z nedbanlivosti a ohrozenia posádky letu a nasledovalo trestné konanie. Bulvárna tlač mala vel'ký podiel na dramatizácii celej situácii, čím podporovala dehumanizáciu kapitána a viedla k jeho samovražde. Takéto prípady nie sú ojedinelé ani u nás, kedy obvinení lekári sú odsúdení za prečin usmrtenia pacienta. A aj ked' to môže priniest' pocit spravodlivosti, Hilfiker (1984) upozornil na dysfunkčné spôsoby vyrovnávania sa lekárov so svojimi vlastnými chybami. Často reagujú hnevom, projekciou viny, môžu konat' defenzívne alebo obviňovat' iných členov tímu či pacienta. $Z$ dlhodobého hl'adiska sú niektorí lekári hlboko ranení, vyhoria alebo hl'adajú útechu v alkohole a iných drogách. Tým pádom je učenie z nehody nemožné, poprípade minimálne, nakol'ko vel'mi zriedka sa stáva zo strany kolegov, že si uvedomia rovnakú zranitel’nost' k podobným chybám.

Kohnová, Corriganová a Donaldsonová (2000) v knihe „To Err Is Human: Building a Safer Health System " ponúkajú riešenia vo forme bezpečnostných systémov či vytvorení centier pre bezpečnost' pacientov. Aj napriek tomu, že bolo vytvorených niekol'ko centier pre bezpečnost' pacientov (Jensen, 2008), nebol zavedený napríklad povinný systém hlásenia správ. Mnohé organizácie majú vytvorené systémy na zaznamenávanie nehôd a udalostí, u ktorých došlo k chybám. Tieto systémy sú však inkonzistentné v mnohých rozmeroch ako obsah, formát hlásení, samotná kl'účová skupina, nakol'ko je správa povinná alebo dobrovol'ná, dôvernost', možnost' anonymity v systéme. Ako poznamenali Holden \& Karsh (2007), mali by sa robit' cielené rozhodnutia ohl'adom toho, čo by malo byt' hlásené, kto by mal podávat' správu, ako by 
sa informácie mali oznamovat' a nakoniec, čo by sa malo s výslednými správami robit'. Ďalším problémom $v$ správach je, že nehody a incidenty sú podané nedostatočne a existujú nerovnomerné hlásenia o nehodových udalostiach medzi pracovníkmi v závislosti od ich postavenia (Lawton \& Parker, 2002). Dôvodom týchto rozdielov a nedostatkov v hláseniach môžu byt' bariéry ako vysoké pracovné zat'aženie a zaneprázdnenie (Suresh et al., 2004), neochota, ale i nedostatok znalosti o potrebe nahlasovania, pochybnosti, kto by mal podávat' správy (Robinson et al., 2002), neistota, ako to nahlásit' (Jeffe et al., 2004) alebo obavy z možných dôsledkov (Weingart et al., 2000). Prevládanie kultúry viny prispieva k neochote hlásit' takéto incidenty aj tým, že mnohé štátne a federálne systémy sú zriadené na disciplinárne účely. Cullen s kol. (1995) v jednej štúdii preukázali značné rozdiely v názoroch na to, čo by sa malo hlásit' a čo je reálne hlásené. Práve táto diskrepancia môže byt' príčinou domnienky, že hlásenie chýb je disciplinárnym nástrojom. Kultúra obviňovania a viny v oblasti zdravotnej starostlivosti, ktorá nadmerne zdôrazňuje disciplinárne opatrenia alebo iné nepriaznivé dôsledky, ako je hanba či zameranie pozornosti na chybujúceho jednotlivca, tak odrádza praktizujúcich od pripúšs’ania chýb. Paradoxom však je, že bez podávania a hlásenia správ sa nemožno dopracovat' $\mathrm{k}$ jednotnému systému a ani k samotnému ciel'u týchto správ, a to, k identifikácii l’udských faktorov v nehodových situáciách (Holden, \& Karsch, 2007).

\section{Analýza chýb ako prostriedok zmeny?}

Ako sme spomínali vyššie, v súčasnosti sa apeluje na kultúru spravodlivosti, podl'a ktorej by sa všetky nehody, ktoré majú za následok smrt' alebo vážne zranenia mali vyhodnotit' s ciel'om vylepšenia systému a redukcie podobných prípadov v budúcnosti. Aj chyby, ktoré nevedú k vážnym dôsledkom predstavujú príležitost' $\mathrm{k}$ zlepšeniu fungovania a prevencia chýb znamená zlepšenie na všetkých úrovniach zdravotnej starostlivosti.

James Reason (1990) analyzoval viaceré nehody s ciel'om preskúmat' úlohu systémov a individuálneho príspevku v týchto nehodách. Podl'a autora, ak vel'ké systémy zlyhajú, je to spôsobené viacerými chybami, ktoré sa vyskytujú spoločne v neočakávanej interakcii vytváraním ret’azca udalostí, v ktorých sa chyby rozrastajú a vyvíjajú. Jednotlivci či samotné oddelenie vlastnia iba nejaký kúsok liečebného systému, ale spravidla nemajú vplyv na zdravotný systém ako celok. Podobne, Aveling et al. (2016) skúmali prípadové štúdie v afrických a anglických nemocniciach. Autori potvrdili, že bezpečnost' pacientov závisí od viacerých zdravotníckych poskytovatel’ov a systému. Jednotlivec, ktorý bol najviac blízko incidentu a mohol by sa považovat' za vinníka, bol plne zodpovedný len zriedkavo. Napríklad, jedna sestra v Sakutre zabudla pred operáciou podat' profylaktické antibiotiká, ale takéto chyby boli skôr odrazom systémových problémov v rámci organizačného kontextu. Prínos jednotlivca k nehodám nie je úplne zanedbatel'ný, ale zameriavat' sa výlučne na incidenty nám ponúka len čiastočné vysvetlenie. Ako poukázali autori, štandardy, ktoré zdravotnícki pracovníci mali spíňat' im neboli vždy jasné, často chýbali klinické alebo administratívne protokoly alebo vedomost' o tých, ktoré existujú. Na druhej strane, v anglických nemocniciach bolo protokolov príliš mnoho, často sa menili a pracovníci uviedli, že nie je možné sledovat' všetky aktualizácie a zmeny. Pracovníci často identifikovali medzery medzi tým, čo by mali robit’ a dostupnými zdrojmi, poukazovali na problémy so zariadením, personálom, riadením a infraštruktúrou. Týmto nechceme povedat', že by sa nemalo apelovat' na individuálnu zodpovednost' 
zdravotníkov a myslíme si, že každý pracovník musí mat' spôsobilost' a charakter rozhodujúci pre výkon v danej profesii. Avšak, súhlasíme s Avelingom et al. (2016), že tieto individuálne kompetencie a profesionálne cnosti sa neposilňujú a neudržiavajú systémom a systém nie vždy podporuje a zaist'uje bezpečnost'.

Napríklad autori preukázali, že vo všetkých nemocniciach bol identifikovaný vplyv medzi pomerom zamestancov a pacientmi na kvalitu poskytovanej starostlivosti a bezpečnost', ale $\mathrm{z}$ dôvodu externe stanovených úrovní financovania a obmedzenej dostupnosti sa to neriešilo. Autori takisto zistili, že zdravotnícki pracovníci často pracujú tvrdo, hl'adajú kreatívne riešenia a morálna agenda jednotlivcov je $\mathrm{v}$ takýchto prípadoch hranicou medzi poškodením a pomocou. Niekedy sa $\mathrm{v}$ dôsledku nepriaznivého charakteru prostredia cítili demoralizovaní a vyčerpaní. Mnohí sa cítili zbavení kontroly nad situáciou, čo príležitostne znamenalo, že neprijímali vlastnú zodpovednost' aj v prípade, kedy mohli pomôct' alebo ul'avit' pacientovi. Ako príklad uvádzajú staršieho pacienta, ktorý spadol z postele a zostal niekol'ko minút na zemi, dokým personál neupratal okolité postele, napriek tomu, že si boli vedomí a informovaní o tejto situácii. Takisto sa stážisti alebo iní zdravotnícki personál pokúšajú o úlohy, ktoré sú za ich kompetenciami, bud' za účelom získania skúsenosti alebo z dôvodu, že $\mathrm{v}$ danom okamihu nebol nikto $\mathrm{k}$ dispozícii. $\mathrm{V}$ niektorých prípadoch však môže dôjst' $\mathrm{k}$ vážnemu poškodeniu pacienta.

Môžeme zhrnút', že podl'a niektorých autorov na ochranu pacientov pred možným poškodením vdlhodobom horizonte, ako aj na udržanie profesionálnej komunity, je nevyhnutné uplatňovanie sociálnej kontroly prostredníctvom sankcií. Podl'a týchto autorov sa niektoré chyby môžu považovat' za „odpustitel'né“, zatial' čo iné sú dôkazom morálneho zlyhania, pretože sa nedodržiavajú záväzky, ktoré si ich profesia vyžaduje. V takom prípade sú chyby sankciovatel'né (Bosk, 2003). Na druhej strane, pri väčšine situácií v zdravotníctve nie je jasná a jednoznačná osobná zodpovednost' a nie sú vytvorené systémy, ktoré by rozdel'ovali úmyselný čin od neúmyselného alebo určili zodpovednost' medzi systémom a jednotlivcom. Podl'a nás by naša pozornost' mala byt' zameraná skôr na vzájomnú prepojenost' individuálneho správania, organizačného a systémového kontextu. V literatúre sme nenašli jednoznačné riešenia, avšak niektorí autori poskytujú návrhy.

Podl'a Edwina (2009) by inštitúcie, ktoré majú v rukách moc a kontrolu usmernení, mali poskytovat' $\mathrm{v}$ takýchto prípadoch emočnú podporu všetkým zdravotníkom. Tým môže byt' ul'ahčená morálna odvaha priznat' chybu. Dekker (2003) navrhuje, aby jednotlivci podiel'ajúci sa na nešt’astiach a katastrofách boli zodpovední tým, že rozprávajú svoj príbeh. Niektoré výskumy (Hinyard \& Kreuter, 2007; Monk et al., 2016) poukazujú na hodnotu príbehu pri príprave na dynamické a komplexné situácie. Práve to by mohli využivat' napríklad systémy, namiesto inkriminovanej formy zodpovednosti, ktorá v skutočnosti spomal'uje kvalitu v prvom rade tým, že l'ud'om znižuje motiváciu tieto príbehy rozprávat' (Dekker, 2003). Podl'a Avelinga et al. (2016) jednou z hlavných povinností zdravotníckych organizácií a inštitúcií nie je len vytvorenie algoritmu pre distribúciu viny, ale aj podpora, kultivácia a udržanie individuálnej spôsobilosti a cnosti. Bell et al. (2011) poskytujú príklad, ako by mohlo vyzerat' učenie sa z chýb a kolektívna zodpovednost' pre primárnu starostlivost' pri oneskorenej diagnóze pacienta s rakovinou. Navrhujú, aby sa priamo a otvorene pacientovi komunikovala chyba a informovali potrebné inštitúcie. Pacient by sa potom zúčastnil na analýze udalostí a mohli sa tak odhalit' 
príčiny oneskorenej diagnostiky a zaviedol plán prevencie, na ktorom by sa spolupodiel'ali inštitúcie. Autori zachádzajú aj d’alej a navrhujú, aby sa inštitúcie podiel'ali na komunikácii s orgánmi, ktoré sa zaoberajú zanedbaním starostlivosti a ponúkli pacientovi primeranú kompenzáciu. Všetky zúčastnené strany sa nakoniec stávajú priamymi účastníkmi zlepšenia systému na dennej báze, informujú o nedostatkoch, zlepšujú komunikačné a tímové zručnosti a uplatňujú mentalitu spoločného spolupodiel'ania sa na bezpečnosti pacientov.

\section{Záver}

Zodpovednost' bola pôvodne vytvorená ako individuálna doména, avšak popri komplexnom systéme zdravotnej starostlivosti sa rozšírila na úroveň kolektívnu. Aj napriek tomu, že v našej spoločnosti prevláda kultúra viny, chyby zdravotníckych pracovníkov by mali byt' podstatné pre celú organizáciu a systém, pretože ponúkajú dôležitú lekciu. To si podl’a nás vyžaduje aj kultúrnu zmenu pohl'adu, aby celá spoločnost' pochopila, že bezpečnost' je syntézou zodpovednosti a spol'ahlivosti individuálneho profesionála, inštitúcií a zdravotníckeho systému.

Odborník získava nástroje, aby mohol adekvátne reagovat' na požiadavky pacienta a na záväzky voči spoločnosti. Avšak, systém zdravotnej starostlivosti získava nástroje na kontrolu odborníka, s možnost’ami monitorovat' umiestnenie odborníkov v daných pozíciách, v závislosti od ich schopností a úrovne výkonu (Genovese et al., 2017). V literatúre sme nenašli jednoznačné odpovede, ako efektívne zlepšit' bezpečnost' pacienta, no čoraz viac autori zdôrazňujú tzv. spravodlivú kultúru, v ktorej chyby ponúkajú príležitost' pre učenie sa. Možno by takéto pojmy zodpovednosti a spravodlivosti mohli presunút' kultúru obviňovania do kultúry bezpečnosti a plnit’ to, čo hlásal Hippocrates: „Pomôct' alebo prinajmenšom neškodit'. “

\section{Pod'akovanie}

Tento príspevok je súčast’ou riešenia projektu VEGA 2/0070/18 Kognitívne a sociálne zručnosti podporujúce kvalitu rozhodovania a celkového výkonu práce u členov posádok záchrannej zdravotnej služby.

\section{Literatúra}

ASQ (2007). Nurse Charged With Felony in Fatal Medical Error. Retrieved from http://asq.org/qualitynews/qnt/execute/displaySetup?newsID=1056.

Aveling, E., Parker, M., \& Dixon-Woods, M. (2016). What is the role of individual accountability in patient safety? A multi-site ethnographic study. Sociology of Health \& Illness, 38(2), 216-232. https://doi.org/10.1111/1467-9566.12370

Ballantyne, T. (2002). Peers support sieged pilots: Taipei accused of glossing over airport deficiencies. Orient Aviation, 6, 20-21.

Bendová, J., \& Vaverková, I. (2012). Bezpečnost' pacienta v primárnej starostlivosti na Slovensku. V̌̌eobecné lekárstvo, 9(1), 32-33.

Bell, S. K., Delbanco, T., \& Anderson-shaw, L. (2011). Accountability for medical error moving beyond blame to advocacy. CHEST, 140(2), 519-526. 
Bosk, C. L. (2003). Forgive and Remember: Managing Medical Failure. Chicago, IL: University of Chicago Press.

Cullen, C. J., Bates, D. W., \& Small, S. D. (1995). The incident reporting system does not detect adverse drug events: a problem for quality improvement. Joint Commission Journal on Quality and Patient Safety, 12, 541-52. https://doi.org/10.1016/S1070-3241(16)30180-8

Dekker, S. W. A. (2003). When human error becomes a crime. Human Factors and Aerospace Safety, 3(1), 83-92. Retrieved from http://sidneydekker.com/wpcontent/uploads/2013/01/ErrorCrimeDekker.pdf

Dekker, S. (2012). Just culture: Balancing safety and accountability. CRC Press: Ashgate Publishing.

Donabedian, A. (1996). Evaluating the quality of medical care. Milbank Quarterly, 83(4), 691--729. https://doi.org/10.2307/3348969

Edwin, A. K. (2009). Non-disclosure of medical errors an egregious violation of ethical principles. Ghana Medical Journal, 43(1), 34-39. Retrieved from https://www.ncbi.nlm.nih.gov/pmc/articles/PMC2709172/

Gallagher, T. H. \& Levinson, W. (2004). The Wrong Shot: Error Disclosure (AHRQ). Retrieved from http://www.ihi.org/education/IHIOpenSchool/resources/Pages/Activities/AHRQCaseStudy WrongShotErrorDisclosure.aspx.

Genovese, U., Sordo, S. D., Pravettoni, G., Akulin, I., Zoja, R., \& Casali, M. (2017). A new paradigm on health care accountability to improve the quality of the system: four parameters to achieve individual and collective accountability. Journal of Global Health, 7(1), 6-9. https://doi.org/10.7189/jogh.07.010301

Gurňáková, J. (2017). Mýlit’ sa je nebezpečné alebo potrebuje medicína psychológiu? In M. Blatný, M. Jelínek, P. Květon, D. Vobořil (Eds), Sociální procesy a osobnost 2017: Sborník př́spěvkí. Brno: Masarykova univerzita.

Gorovitz, S., \& MacIntyre, A. (1975). Toward a theory of medical fallibility. Philosophy, 5(6), 13-23. https://doi.org/10.2307/3560992

Hilfiker, D. (1984). Facing Our Mistakes. The New England Journal of Medicine, 310(2), 188-222. https://doi.org/10.1056/NEJM198401123100211

Hinyard, L. J., \& Kreuter, M. W. (2007). Using narrative communication as a tool for health behavior change: A conceptual, theoretical, and empirical overview. Health Education \& Behavior, 34(5), 777-792. https://doi.org/10.1177/1090198106291963

Holden, R. J., \& Karsh, B. (2007). A review of medical error reporting system design consideration and a proposed cross-level systems research framework. Human Factors, 49(2), 257-276. https://doi.org/10.1518/001872007X312487

Jeffe, D. B., Dunagan, W. C., \& Garbutt, J. et al. (2004). Using focus groups to understand physicians' and nurses' perspectives on error reporting in hospitals. Joint Commission Journal on Quality and Safety, 30(9), 471-479. https://doi.org/10.1016/S1549-3741(04)30055-9

Jensen, C. B. (2007). Sociology, systems and (patient) safety: knowledge translations in healthcare policy. Sociology of Health \& Illness, 30(2), 309-324.

https://doi.org/10.1111/j.1467-9566.2007.01035.x 
Kohn, L. T., Corrigan, J. M. \& Donaldson, M. S. (2000). To Err is Human: Building a Safer Healthcare System. Washington D.C.: National Academy Press.

Lawton, R., \& Parker, D. (2002). Barriers to incident reporting in a healthcare system. Quality and Safety in Health Care, 11, 15-19. http://dx.doi.org/10.1136/qhc.11.1.15

Leape, L. L., Kabcenell, A. I., Gandhi, T. K., Carver, P., Nolan, T.W., \& Berwick, D. M. (2000). Reducing adverse drug events: Lessons from a breakthrough series collaborative. Joint Commission Journal on Quality and Patient Safety, 26(6), 321-331. https://doi.org/10.1016/S1070-3241(00)26026-4

Lerner, J. S., \& Tetlock, P. E. (1999). Accounting for the effects of accountability. Psychological Bulletin, 125(2), 255-275. http://dx.doi.org/10.1037/0033-2909.125.2.255

Lewis, H. D. (1984). Collective responsibility. Philosophy, 23(84), 3-18. https://doi.org/10.1017/S0031819100065943

Marx, D. (2001). Patient Safety and the "Just Culture": A Primer for Health Care Executives. New York: Columbia University.

Meadows, S., Baker, K., \& Butler, J. (2005). The incident decision tree: guidelines for action following patient safety incidents. Advances in Patient Safety, 4, 387-400. Retrieved from https://www.ncbi.nlm.nih.gov/books/NBK20586/pdf/Bookshelf_NBK20586.pdf

Monk, G., Sinclair, S., \& Nelson, M. (2016). Exploring healthcare professionals' use of narrative mediation approaches to address disclosure and apology in the aftermath of medical errors. Narrative and Conflict: Explorations of Theory and Practise, 3(1), 24-43. https://doi.org/10.13021/G8ncetp.v3.1.2016.531

Narveson, J. A. N. (2002). Collective responsibility. The Journal of Ethics, 6(1), 179-198. https://doi.org/10.1023/A:1015823716891

Oyebode, F. (2006). Clinical errors and medical negligence. Advance in Psychiatric Treatment, 12, 221-227. https://doi.org/10.1159/000346296

Perrow, Ch. (1999). Normal accidents: Living with high-risk technologies. Princeton, N.J: Princeton University Press.

Reason, J. (1990). Human error. New York, NY, US: Cambridge University Press.

Reason, J. T. (1997). Managing the risks of organizational accidents. Aldershot, Hants, England: Ashgate.

Nunes, R., Brandao, C., \& Rego, G. (2011). Public accountability and sunshine healthcare regulation. Health Care Analysis, 19(4), 352-364. Retrieved form https://link.springer.com/article/10.1007/s10728-010-0156-6

Robinson, A. R., Hohmann, K. B., Rifkin, J. I., Topp, D., Gilroy, C. M., Pickard, J. A., \& Anderson, R. J. (2002). Physician and public opinions on quality of health care and the problem of medical errors. JAMA Internal Medicine, 162(19), 2186-2190. https://doi.org/10.1001/archinte.162.19.2186

Sagan, S. (1993). The Limits of Safety: Organizations, accidents and nuclear weapons. Princeton, NJ: Princeton University Press.

Starfield, B. (2000). Is US health really the best in the world? JAMA, 284(4), 483-485. https://doi.org/10.1001/jama.284.4.483

Stoyanova, R. G., Rayacheva, R. D., \& Dimova, R. T. (2012). Economic aspects of medical errors. Folia Medica, 54(1), 58-64. https://doi.org/10.2478/v10153-011-0079-5 
Suresh, G., Horbar, J. D., Plsek, P., Gray, J., Edwards, W. H., Shiono, P. H., \& Ursprung, R. (2004). Voluntary anonymous reporting of medical errors for neonatal intensive care. Pediatrics, 113(6), 1609-1618. https://doi.org/10.1542/peds.113.6.1609

Thompson, D. F. (1980). Moral responsibility of public officials: The problem of many hands. The American Political Science Review, 74(4), 905-916. https://doi.org/10.2307/1954312

Wachter, R. M. (2013). Personal accountability in healthcare: Searching for the right balance. BMJ Quality \& Safety, 22(2), 176-182. http://dx.doi.org/10.1136/bmjqs-2012-001227

Wachter, R. M. \& Pronovost, P. J. (2010). Balancing 'no blame' with accountability in patient safety. New England Journal of Medicine, 361(14), 1401-1406. http://dx.doi.org/10.1056/NEJMsb0903885

Waldman, J. D., \& Smith, H. L. (2012). Strategic planning to reduce medical errors: Part IDiagnosis. The Journal of Medical Practice Managment, 27(5), 260-262.

Warrier, S., \& Mcgillen, B. (2011). The evolution of quality improvement. Medicine and Health, Rhode Island, 94, 211-212. Retrieved from http://www.rimed.org/medhealthri/2011-07/2011-07-211.pdf

Weber, M. (1978). Economy and Society. Berkeley: University of California Press.

Weingart, S. N., Ship, A. N., \& Aronson, M. D. (2000). Confidential clinician-reported surveillance of adverse events among medical inpatients. Journal of General Internal Medicine, 15, 470-477.

Wilkinson, S. (1994). The November Oscar incident. Air and Space, February-March.

WHO. (2017). Data and statistics. Retrieved from http://www.euro.who.int/en/healthtopics/Health-systems/patient-safety/data-and-statistics

\section{O autorce}

Mgr. Zuzana Kaššaiová je doktorandkou na Ústave experimentálnej psychológie CSPV SAV, v.v.i. K jej odborným záujmom patrí predovšetkým problematika sociálnych zručností v zdravotníckej oblasti.

\section{Kontaktní údaje:}

Adresa: Ústav experimentálnej psychológie, Centrum spoločenských a psychologických vied SAV, v.v.i., Dúbravská cesta 5819/9, 84104 Bratislava - Karlova Ves

E-mail: kassaiova.zuzana@gmail.com

Kaššaiová, Z. (2019). Rôzne pohl'ady na zodpovednost' v zdravotníckom systéme. E-psychologie, 13(2), 47-57. https://doi.org/10.29364/epsy.343 